\title{
EL PROCESAMIENTO ESTATAL DE LAS DEMANDAS POPULARES. EL CASO DE CÓRDOBA, ARGENTINA
}

\section{THE STATE PROCESSING OF POPULAR DEMANDS. THE CASE OF CORDOBA, ARGENTINA}

\author{
Gerardo Avalle*
}

\section{RESUMEN}

Una mirada que se aproxime a los lenguajes que asumen las demandas populares y su inscripción en los intersticios de la política implica, necesariamente, identificar las instancias de traducción —institucional_ donde la potencia de la resistencia es transcrita en los órdenes de la administración pública. En este artículo se efectúa un análisis de la gramática popular mediante técnicas de análisis de discurso y contenido a un conjunto de entrevistas realizadas en el marco de los movimientos sociales en Córdoba, Argentina, durante el periodo 2004-2010. El presente trabajo se organiza en tres apartados: el primero contextualiza la política argentina desde la percepción de los sectores populares, el caso argentino; el segundo, advierte sobre la emergencia de nuevos actores colectivos en el marco de la crisis económica del año 2001; y finalmente, el tercero desarrolla la trayectoria de los dispositivos estatales y las organizaciones populares, abordadas en los apartados anteriores, pero ahora en el territorio de la provincia de Córdoba.

\section{PALABRAS CLAVE: PODER POLÍTICO * MOVIMIENTO SOCIAL * CONFLICTO SOCIAL * ANÁLISIS SEMÁNTICO * DERECHOS ECONÓMICOS Y SOCIALES}

\section{ABSTRACT}

The languages of the popular demands and their inscription in the interstices of the policy, necessarily implies identifying the instances of processing -institutionally- where the power of the resistance is transcribed in the orders of the public administration. That is why an analysis of popular grammar using discourse and content analysis techniques to a set of interviews made within the framework of social movements in Córdoba, Argentina, during the period 2004-2010 was conducted. The present work is organized in three sections: the first contextualizes the Argentinian policy from the perception of the popular sectors; the second one warns about the emergence of new collective actors in the context of the 2001 economic crisis; and finally, the third develops the trajectory of state devices and popular organizations, addressed in the previous sections, but now in the territory of the province of Córdoba.

Universidad Católica de Córdoba, Unidad Asociada al conicet. Colectivo de Investigación El Llano en Llamas, Argentina. 
KEYWORDS: POLITICAL POWER * SOCIAL MOVEMENT * SOCIAL CONFLICTS * SEMANTICS * SOCIAL AND ECONOMIC RIGHTS

\section{INTRODUCCIÓN}

El modo de inscripción de las demandas populares en los espacios públicos es un fenómeno que advierte sobre las relaciones de fuerza en cada sociedad. Particularmente, el modo en que esos horizontes de expectativas son procesados por los dispositivos de gobierno hace visibles las tensiones del presente, los límites de lo posible, $y$ lo que queda por fuera de todo ordenamiento de poder.

Estas formas de nombrar, de construir $y$ de impregnar los sentidos de la política están en permanente tensión. Tanto espacio público, política, como Estado y gobierno son conceptos que, más allá de la institucionalidad que los acompañe, son objeto de una puja incesante de posiciones que advierte sobre las formas de dominación del presente.

En consecuencia, una mirada que se aproxime a los lenguajes que asumen las demandas populares y su inscripción en los intersticios de la política, implica necesariamente identificar las instancias de traducción - institucional - donde la potencia de la resistencia es transcrita en los órdenes de la administración pública. Ello no supone, de modo repentino, la desaparición del conflicto; al contrario, desde esta perspectiva es el comienzo del desacuerdo y la resistencia a ser procesados por el sistema político. En este sentido, observar los lenguajes con que las políticas públicas $-y$ especialmente las sociales-interpelan $y$ procesan las expectativas populares, permite comprender los dispositivos de gobierno desplegados sobre la población.

La gramática popular advierte sobre el revés de una política de (des)igualdad, y esta es la afirmación que se desarrollará en este texto: la inscripción de los sujetos en los espacios públicos y las demandas por mayor igualdad se enfrentan a un riesgo permanente de desactivación política e inclusión degradada en el lenguaje de la ciudadanía.
La posibilidad de sostener este tipo de afirmaciones requiere de una contextualización - cronológica-que marque, dentro de la trayectoria de las políticas públicas, aquellas transformaciones que las hacen (radicalmente) diferentes de sus antecesoras, a pesar de mantener lenguajes idénticos. En este sentido, la configuración del escenario político y social argentino ha registrado, a grandes rasgos, comportamientos singulares. Específicamente, se refiere a las modificaciones que se comenzaron a registrar en todos los parámetros de relevancia pública: Estado, pobreza, democracia, ciudadanía, derechos. En este texto, se hace parte a esas voces de demanda e impugnación, recuperando aquellos extractos de entrevistas y observaciones de campo realizadas durante varios años en la provincia de Córdoba, Argentina ${ }^{1}$, que permitan comprender

$1 \quad$ El corpus de datos se conforma a partir del trabajo en diferentes proyectos de investigación llevados a cabo por el Colectivo de Investigación El Llano en Llamas. A continuación se indica el periodo de duración de los proyectos y el nombre de los mismos. 2012-2016 Proyecto: "Territorios en Disputa. Un estudio sobre los conflictos territoriales urbanos y rurales en la Provincia de Córdoba". Dir: Ma. Alejandra Ciuffolini. Proyectos PIO 2011, Ministerio de Ciencia y Tecnología de la Provincia de Córdoba. 2014-2016 Proyecto: "Semántica de la conflictividad social en Córdoba (período 2013-2014)" Dir. Ma. Alejandra Ciuffolini. Secyt-Universidad Nacional de Córdoba. 2014-2010 Proyecto: "Apropiación/Expropiación de territorialidades sociales. Análisis comparativo de procesos de erradicación/relocalización de fracciones sociales empobrecidas, en ciudades argentinas". Dir. A. Núñez y M.A. Ciuffolini. Universidad Nacional de Mar del Plata, Foncyt. 2010-2011. Proyecto: "Cuando lo cotidiano se vuelve trágico: riesgo y seguridad en los procesos de relocalización territorial en la Ciudad de Córdoba”. Dir: P. Scarponetti. Co-Dir: Ma. Alejandra Ciuffolini. Secyt, Universidad Nacional de Córdoba. 2008-2007 Proyecto: "Territorios de utopías. Experiencias y expectativas en las luchas sociales urbanas y campesinas de hoy". Dir: M.A. Ciuffolini. Universidad Católica de Córdoba. 
estas transformaciones y continuidades que el relato popular advierte.

Córdoba es un estado situado geográficamente en el centro de Argentina, con una población de más de 3 millones de habitantes, siendo la segunda provincia más poblada, luego de Buenos Aires. Las relaciones con la administración central siempre han sido tensas, independientemente del signo político de los respectivos gobiernos. Durante los años 90, la provincia fue gobernada por distintas fracciones del centenario partido Radical (UCR), mientras la administración central era ocupada por el peronismo (PJ). A finales de década, el gobierno local pasa a manos del PJ, $y$ el gobierno nacional es dirigido por el mismo signo político. Sin embargo, los vínculos nunca fueron pacíficos y muchas de las veces excedieron las vías institucionales de resolución (Avalle e Ibáñez, 2011).

\section{METODOLOGÍA}

La estrategia metodológica seguida consiste en la conformación de un corpus discursivo como referente empírico de la problemática aquí tratada, constituido por un conjunto de entrevistas realizadas en diferentes momentos temporales a diversos actores del campo popular cordobés, con el principal interés de recuperar, mediante el análisis de contenido, aquellas gramáticas que expresaban el clima de época, sus tensiones, demandas $y$ articulaciones, $y$ al mismo tiempo, la configuración de las relaciones de fuerza en cada momento.

Los discursos muestran una continuidad quasi estructural frente al modo de pensar lo político y lo público. De ahí que se trabaje con registros de entrevistas de diferentes años, durante un lapso de 10 años aproximadamente, con el objeto de rescatar aquellas continuidades, rupturas y desplazamientos que arroja la gramática popular, ya sea en tiempos de crisis sociales y políticas, o en tiempos de mayor estabilización política.

El presente trabajo se organiza en tres apartados: el primero, contextualiza, desde la percepción de los sectores populares, el caso argentino; el segundo, advierte sobre la emergencia de nuevos actores colectivos en el marco de la crisis económica del año 2001; y finalmente, el tercero desarrolla la trayectoria de los dispositivos estatales $y$ las organizaciones populares, abordadas en los apartados anteriores, pero ahora en el territorio de la provincia de Córdoba.

\section{ARGENTINA: LA PERCEPCIÓN POPULAR DE UN MODELO EXCLUYENTE}

Argentina inicia un proceso neoliberalizador a partir de la instauración del gobierno de facto protagonizado por la dictadura militar en 1976. Este se profundiza bajo las bases del conocido "consenso de Washington" durante la presidencia de Carlos Menen (1989-1999). Durante esta década, los principales indicadores sociales (pobreza, desempleo, indigencia, salud, educación, etc.) se vieron fuertemente afectados.

La dinámica de implementación de reformas estructurales fue drástica y pocas veces consensuada. Ello supuso importantes desplazamientos de los actores colectivos involucrados en la toma de decisiones, el realineamiento en el campo popular, $y$ la emergencia de nuevos actores organizados en torno a demandas reivindicativas básicas como el acceso a derechos sociales, coberturas asistenciales y contención ante el creciente desempleo. Esta situación terminó implosionando en los dramáticos acontecimientos que tuvieron lugar a finales del año 2001 y principios de 2002, reflejo de una crisis y reconfiguración del sistema político, económico y social.

La crisis de 2001 reafirmó la dinámica del capitalismo local: no existen transiciones ordenadas, sino quiebres y permanentes disputas entre las distintas fracciones del capital. A diferencia de lo que ocurre en el país vecino (Brasil), el capital nacional argentino siempre fue dependiente de la política estatal y de la dinámica del capital internacionalizado. Los mercados locales (agrícola, industrial y financiero) siempre se mostraron dóciles al capital internacional, incapaces de construir hegemonía dentro de un proyecto de acumulación, lo que implicó sucesivas crisis y transiciones caóticas entre cada modelo económico (Aspiazu y Basualdo, 2012; Sidicaro, 2006).

Posterior al año 2001, el Estado aparece como el "mediador" que confronta con los 
principales grupos concentrados de poder; $y$ trata de consolidar un bloque hegemónico que se centre en un capital nacional productivo, industrialización de la materia prima y estímulo al consumo, además de promover la renta financiera y la dinámica extractiva de recursos naturales, situación que guarda cierta similitud con el resto de la región (Seoane, 2012; CEPAL, 2011; Katz, 2010; Gudynas, 2009).

Esta configuración del campo de fuerzas también se tradujo en una reconfiguración del discurso político y en las propias prácticas de la estatalidad (Svampa, 2005). Parafraseando a Dagnino (2006), lo que se observa es un proceso de "confluencia perversa" entre un proyecto político neoliberal y otro más democratizante y participativo. Resulta que, detrás de un discurso de inclusión que comienza a aparecer fuertemente a partir del año 2003, se observan trayectorias disímiles en lo que refiere a la implementación de las políticas públicas (sociales, laborales, de infraestructura, etc.) ya sean tanto a nivel nacional, pero muy especialmente en las administraciones provinciales.

En este marco, se indaga a partir de los testimonios provistos por los sectores populares, cómo es percibida esta dinámica del sistema político, $y$ los desfasajes que aparecen entre el discurso y la práctica concreta desplegada por la estatalidad. Un análisis que luego de varios años permite mirar en retrospectiva $y$ problematizar los conflictos, distanciándose del momento de ebullición de las luchas, al tiempo que las condiciones del presente sirven de contrapeso frente a lo que hoy se intenta releer.

En este sentido, la situación que se expresa en los relatos respecto de la experiencia local no se restringe a su faceta económica, sino que se inscribe dentro de una dinámica más general de configuración de las fuerzas políticas en relación a la dinámica del capital. De ahí que la debacle neoliberal comience en la práctica y en los relatos a partir de la última dictadura militar. La herencia de la dictadura no solo fueron modelos económicos excluyentes $y$ restrictivos ("para pocos"), sino también la tragedia y el genocidio ("destruida") para toda una generación de militantes.
Los que tenemos hijos queremos dejarles algo, ya que nuestra generación, la famosa generación del setenta, ha sido destruida por el proceso, $y$ los que quedamos somos la borra, $y$ por eso tenemos los dirigentes que tenemos (Coordinadora de Asambleas Barriales, vecino 01, comunicación personal, Córdoba, 2002).

... con ese eufemismo se planteaba que había que privatizar la salud, privatizar los ferrocarriles, privatizar(-) era la receta concreta del fin del Estado de bienestar, de un modelo, que con sus pro y sus contras, veníamos construyendo los argentinos (Central Sindical, Central de Trabajadores Argentinos, sindicalista 01, comunicación personal, Córdoba, 2005).

El proceso neoliberal es claramente identificado como un producto gestado a partir del último golpe cívico militar. Es precisamente en ese acto constitutivo donde se inicia un cambio de paradigma $y$ las generaciones siguientes son las que debieron atravesar las consecuencias estructurales del cambio de políticas y la primacía del mercado.

Pero nosotros luchamos contra un modelo que estuvo vigente en esta Argentina desde la dictadura militar en adelante que bueno, que fue el modelo que nos dejó como estamos digamos, hechos mierda. Y bueno, peleamos básicamente con eso y con cualquiera que lo represente a ese modelo (Movimiento Piquetero, Barrios de Pie, piquetero 06, comunicación personal, Córdoba, 2005).

... en los noventa fue Menem, en el 2001 De la Rúa, hoy qué sé yo, acá en la Provincia De la Sota... ¿me entendés? Gente que está ligada al liberalismo y que... siguen construyendo un país para pocos y no para todos (Movimiento Piquetero, Barrios de Pie, piquetero 05, comunicación personal, Córdoba, 2005). 
Por esta razón, cuando se recupera la tesis de la "confluencia perversa" de proyectos políticos (Dagnino, 2006) y se afirma que dentro de cada relación de fuerza dominante persisten las consecuencias y tensiones de cada fracción de poder, no se hace más que intentar comprender la aparente contradicción entre el relato de la "inclusión" que la política "neoliberal" expresa, esto es, la inscripción de la política estatal en un lenguaje de derechos, un estado presente, interventor, pero bajo un marco global dominado por las reglas del mercado, $y$ la percepción social de cierta continuidad de la situación de exclusión y desintegración social en el presente.

... hablar de desocupación en la Argentina es hoy, después de todo el proceso de privatizaciones, es hablar de un problema estructural que no se va a solucionar de un día para otro o con discursos bonitos. Pibes que a la mañana van $y$ toman el desayuno en la escuela, comen en el comedor de la escuela, a la tarde van a la copa de leche, y a la noche pasan por el comedor de alguna organización para retirar la comida. Eso hace ya 8 años atrás que viene sucediendo, qué perspectiva puede tener un pibe que se ha criado de esa manera (Movimiento Piquetero, Movimiento Teresa Rodríguez, piquetero 02, comunicación personal,Córdoba, 2005).

El salario nuestro es consecuencia de todas las medidas de ajuste que se aplicaron a la última década, donde obviamente nos redujeron nuestro poder adquisitivo $y$ otros sectores han hecho tremendas $y$ hacen ganancias (Sindicato, Asociación de Trabajadores del Estado, sindicalista 01, comunicación personal, Córdoba, 2006).

Es que la crisis de un proyecto político (económico, social, cultural) que en cierta forma se expresó en los acontecimientos del año 2001, no supuso una ruptura total con la institucionalidad y los modos de participación políticas instituidas durante las décadas previas. En este sentido, durante los 90, la construcción democrática y de ciudadanía discurrió, utilizando las palabras de Dagnino (2006), en la consolidación de un "proyecto neoliberal" que logró ocultar, temporalmente, las tensiones entre Estado, mercado y sociedad.

Esto supuso la privatización del espacio público, su fragmentación, la retracción del Estado y la producción de un ciudadano consumidor. Ese marco de acción, de prácticas culturales $y$ de formas institucionales no desapareció; en última instancia, comenzó a reconfigurarse. Una tensión inmanente a la constitución de dos proyectos, que en cierto modo confluyen contemporáneamente (y perversamente) en una "forma" de relación gerencial entre Estado y sociedad. Sin embargo, los contenidos de los proyectos no confluyen, el conflicto entre ellos se torna más oculto.

El relato que sigue a continuación expresa esa tensión entre una práctica política que intenta desandar un modo de concebir lo público y lo político, y por otro lado, la posición subjetiva que referencia $y$ ancla a los individuos dentro del sistema social; un horizonte que se vuelve chato, donde las políticas o estrategias de subsistencia no logran convertirse en prácticas de autogobierno y autogestión.

Las Asambleas, tratando de construir una cuestión novedosa que intente un sentido de justicia a través de la participación política fuerte, se encuentran con límites muy concretos, ninguno de los asambleístas se ha planteado salirse como ciudadano, como contribuyentes, del sistema económico, político y financiero donde estamos... las Asambleas no han planteado una rebelión fiscal... hay que incrementar en nuestros temas de deliberación... temas que tengan que ver con la gestión pública de lo común... de las políticas aplicadas a nivel municipal, provincial y nacional (Asamblea Plaza Los Naranjos, vecino 01, comunicación personal, Córdoba, 2002).

Los relatos de las personas entrevistadas se deslizan dentro de un conjunto de argumentos que van advirtiendo sobre el sentir de la población en cada contexto. A finales de los 
90, se expresa un sentimiento de fuerte desafección de la población respecto a la política y sus instituciones, producto de décadas de individualismo y ciudadanía mercantilizada $y$ "contribuyente"; sin embargo, es también en ese contexto que comienzan a hacerse fuertes discursos de impugnación institucional y emergencia de nuevas formas organizativas alternativas a los canales habituales de participación.

Como se advierte en el relato de las personas entrevistadas, la mirada hacia el Estado se va desplazando desde un rechazo e impugnación total, acrecentado luego de la crisis del año 2001 en el caso argentino, donde la institucionalidad es percibida como algo ajeno o distante del sentir cotidiano de la población y la élite gobernante entra en una instancia de alta ilegitimidad, para luego convertirse en el centro de las demandas en los tiempos actuales.

Desde el principio sentimos la necesidad de juntarnos a discutir los temas que estaban pesando en nuestras vidas... gente que busca la contención entre sus pares, participando de las Asambleas... las Asambleas están conformadas por la porción más cercana al pueblo, por cada vecino (Asamblea Alto Alberdi, vecino 01, comunicación personal, Córdoba, 2002).

...todo el esfuerzo que se haga desde la asamblea es construir un poder alternativo que le discuta totalmente la posición al Estado (Asamblea Plaza Los Naranjos, vecino 02 , comunicación personal, Córdoba, 2002).

... desconocemos la autoridad municipal, desconocemos todo tipo de legislación que intente impedir nuestro desarrollo... desconocemos esos instrumentos como parte de una práctica que... intenta aplastarnos como pueblo (Asamblea $\mathrm{B}^{\circ}$ San Martín y Los Paraísos, vecino 01, comunicación personal, Córdoba, 2002). ...ni los partidos políticos ni el Estado han sabido proteger este derecho básico de cualquier sociedad que es el de alimentarse y reproducirse biológicamente... la sociedad ya no cree en las instituciones porque no sostienen ya normas $y$ valores... La gente no cree en el Estado... $y$ es lógico, es lo correcto (Asamblea Seccional 14, vecino 01, comunicación personal, Córdoba, 2002).

\section{NUEVAS FORMAS ORGANIZATIVAS, NUEVOS DISCURSOS, NUEVOS PROYECTOS}

Este escenario de antipolítica, contrahegemonía o democracia directa que se generó a fin de siglo, impactó en la estructura institucional, en los discursos públicos y en las formas organizativas que se dieron para sí los sectores populares. Los relatos antes citados refieren, principalmente, a dos tipos organizativos diferentes. Uno muy propio del escenario de crisis, que fueron las "asambleas barriales", cuya duración fue corta en el tiempo, pero fue el espacio donde se concentró un amplio conjunto de la población que no encontraba en las vías tradicionales de participación un espacio de canalización de sus demandas. La dinámica asamblearia consistió en recrear los espacios de deliberación y acción colectiva, pero, sobre todo, comenzar a reconstruir los lazos sociales fuertemente corroídos por el individualismo.

Por su parte, los movimientos piqueteros son organizaciones que se gestaron como consecuencia del desempleo masivo durante la década anterior, que terminó por expulsar en el año 2002 a más del 25\% de la población del mundo del trabajo. Los "piqueteros" se caracterizaron por implementar las medidas de acción directa, entre ellas, los piquetes o cortes de ruta, como su principal práctica para forzar una respuesta concreta del Estado.

Inevitablemente, este contexto implicó un cambio en los modos de acción, intervención y operatoria de la estatalidad. El fin de siglo vino acompañado en toda la región con un aire "renovador". Lenguaje que incluso permeó el discurso de los organismos financieros internacionales, incorporando una perspectiva más 
"social" en el tratamiento de las problemáticas que surgían como consecuencia de la tenaz defensa del modelo de mercado. Así, las estructuras institucionales, más allá de toda posible resistencia al cambio, se vieron empujadas a un nuevo escenario político. El Estado vuelve a aparecer como responsable de las condiciones de vida de cada individuo y destino colectivo de la población.

En este marco, lo que resulta interesante es indagar las ausencias y continuidades que contienen esos discursos, en tanto remanentes de viejos proyectos políticos en coexistencia con los nuevos. Es que cada lógica de la estatalidad condensa la expresión de las relaciones de fuerza de cada tiempo (cfr. Poulantzas, 2001 y Foucault, 2006); en este sentido, que no sean hegemónicas no implica que hayan desaparecido. De modo que el resabio mercantil es probable que esté siempre presente y al acecho ante cada crisis, apelando a los remanidos argumentos que pusieron en jaque a la estructura de protección social de mediados de siglo pasado.

Los relatos que aparecen a continuación hablan de recuperar el rol del Estado frente a los problemas sociales, la regulación de la economía y la distribución de los recursos. Pero ante este papel activo que se le vuelve a asignar, nuevamente se recuperan las viejas críticas a los estados social-interventores, como la de ser funcionales a la lógica de acumulación capitalista o la de actuar como representantes de los intereses empresariales frente a las demandas laborales.

... creo que el Estado es el que debe centralizar el uso del poder... indispensable, el Estado hay cosas de las cuales puede escapar, es responsable de la salud, la educación, la seguridad, impartir justicia, son cosas tan prioritarias todo lo que hace a la dignidad $y$ al desenvolvimiento del hombre, que el único responsable es el Estado (Asamblea Plaza Los Naranjos, vecino 02, comunicación personal, Córdoba, 2000).

...lo que... el imperialismo busca $y . .$. y el gobierno representando al imperialismo, es poder seguir manteniendo este sistema de ganancias, que ganan unos pocos, es decir, que lucran en América Latina, en África, en Asia... son los grandes carteles, los grandes monopolios (Movimiento Piquetero, Coordinadora de Trabajadores Desocupados Aníbal Verón, Piquetero 04, comunicación personal, Córdoba, 2005).

El modelo emergente se afirmó, en primer lugar, a partir de recuperar la figura del Estado como actor político clave, del cual emanan las directrices de la política y la gestión pública (Mecle, 2010). Ello implicó, necesariamente, un redimensionamiento de toda la estructura de cobertura social y especialmente, los mecanismos de regulación/asistencia a los sectores más desprotegidos (in-empleables, desempleados, menores, mujeres, ancianos, entre otros).

El paradigma emergente requirió, en primer lugar, incorporar en la agenda pública la problemática de la desigualdad como un problema social. Así, el parámetro de la política social cambiaría significativamente su lugar de enunciación. La asistencia seguiría llamándose asistencia, pero su sustento dejaría de ser - al menos de modo directo- la compensación frente a una carencia, el pobre vulnerable. Ahora, el lenguaje comenzaría a circular dentro del campo de la "inclusión" ${ }^{2}$ y de este modo, la apelación de los "derechos humanos" se convertiría en la caja de resonancia para incorporar el derecho a la salud, la educación, la cultura, el trabajo, entre otros, como argumento de sustentación de la penetración estatal.

...si el gobierno implementa programas... qué sé yo, el Hambre Más Urgente, el Manos A La Obra, no es que lo hace porque este gobierno sea BUENO, sino que lo hace en función de la presión social que hay, que le ponen delante de las narices este problema de la comida... bueno... este problema... el del trabajo (Movimiento Piquetero, Movimiento Teresa Rodríguez, Piquetero 02, comunicación personal, Córdoba, 2005). $2 \quad$ Ver Informe de Políticas Sociales del Ministerio de
Desarrollo Social, 2007. 
Dos ejemplos resultan ilustrativos para este caso, el primero es el Plan Jefes y Jefas de Hogar Desocupados creado en 2002, en Argentina, que tiene en sus fundamentos un lenguaje marcado por las nociones de "inclusión", "derechos humanos" y "ciudadanía", comenzando a reconocer situaciones de vida estructurales que antes se las entendía como temporales $y$ aisladas, ya sea de pobreza o desempleo (Avalle, De la Vega y Ferrero, 2009). El segundo ejemplo lo constituye el Plan Jóvenes Más y Mejor Trabajo del año 2003, donde el Estado reconoce la existencia de problemas estructurales en la generación de empleo e inclusión en el mundo laboral de amplios sectores de la población, modificando la estrategia de contención y asistencia que suponían los seguros de desempleo o planes sociales creados a mediados de los 90 como el "Plan Trabajar" (Avalle y Brandán, 2010).

\section{CÓRDOBA, DEMANDAS Y CONFLICTOS TERRITORIALES: PARTICIPACIÓN, TIERRA Y TRABAJO}

Córdoba es una de las provincias más grandes de Argentina. Los índices de pobreza y desocupación tuvieron niveles similares o superiores a la media nacional durante las últimas décadas. Durante los años 70, la desocupación se ubicó aproximadamente alrededor del 3,8\% de la población económicamente activa. En la década siguiente, asciende a 5,8\%. Ambos valores muy inferiores a los obtenidos durante el decenio neoliberal, donde el índice trepó al $11,6 \%$ con un pico de 18,4\% en mayo de 1995. A partir del año 1998, este indicador comienza una escalada que supera los valores históricos alcanzando en el año 2002 a un 21,5\% de la población económicamente activa. Desde ese momento, se registra un descenso sostenido ubicándose en el cuarto trimestre de 2008 en el nivel más bajo desde octubre de 1992 y mayo de 1989, un 7,3\%. En el primer semestre del año 2009, se vuelve a registrar un incremento en este indicador, ubicándose en $8,6 \%$, concluyendo con un promedio anual de $8,68 \%$ de población desocupada. Sin embargo, los niveles de desocupación relativamente "bajos" de las primeras dos décadas, no irían acompañados de la misma manera por los índices de pobreza.
Durante el año 1989, la población en condiciones de pobreza ascendía al 29,1\% y la población indigente superaba a la porción desocupada de la población económicamente activa. En 1990, el comportamiento de estos indicadores es aún más claro, mientras se registra un leve descenso de la desocupación, los niveles de pobreza e indigencia marcan un pico de 44,9\% y $14,5 \%$ respectivamente. En 1991, un leve descenso de la desocupación es acompañado por un descenso en ambos índices. Los efectos regionales que generó la crisis mexicana de 1995, impulsaron nuevamente el crecimiento de la desocupación y la pobreza. Sin embargo, esta última ya no perderá el impulso alcista, alcanzando un $57,5 \%$ en octubre de 2002, superando los niveles del año 1989. En lo que refiere a los niveles de desempleo, la provincia de Córdoba es una de las que mayor volatilidad presenta. Con una tendencia a aproximarse o superar la media nacional, particularmente en los años 1989, 1997, 2002 y 2007-2009. En cuanto a los niveles de pobreza, estos se muestran similares a la media nacional, superándola en las instancias de crisis local o nacional (Avalle, 2010).

El problema habitacional o déficit habitacional ${ }^{3}$, es un fenómeno crónico que se vio agudizado en diferentes momentos por la ausencia de políticas de vivienda para los sectores populares, la creciente pobreza y desempleo durante los 90; actualmente, se suma a ello, la revalorización y puesta en valor de los territorios que ocupaban los asentamientos urbanos. Como se señala en un informe previo, la provincia de Córdoba tiene un significativo déficit habitacional, y más específicamente, un alto porcentaje que registra tenencia irregular de la vivienda $y / 0$ de la tierra donde habitan. Conforme a los datos disponibles, actualmente la provincia de Córdoba presenta un importante déficit en materia habitacional, pero aún más significativo es la

$3 \quad$ En Argentina, el promedio del gasto social en vivienda para la década del 90 no llega a superar el 1,7\% del PBI, incluso evidencia un leve aumento durante los primeros cinco años del 2000 (CEPAL, 2009). En políticas de vivienda específicamente, con la apertura democrática se invertía el 0,7\% del PBI, decayendo a lo largo de la década del 90 al 0,4\% del PBI (Rodríguez y Taborda, 2009). 
cantidad de hogares que registran una tenencia irregular de la tierra $y / 0$ de la vivienda que habitan. En el citado informe, publicado en el año 2011, se señala:

Si se considera de manera conjunta el hacinamiento crítico y condiciones deficitarias de vivienda, el porcentaje de hogares afectados es del 13\%, mientras que los problemas de propiedad afectan a un $35 \%$ de los hogares de la provincia. De ello resulta que casi la mitad de los hogares de la provincia manifiestan algún problema habitacional. Un relevamiento comparativo de precios sostiene que el valor de los terrenos dentro del anillo de la Circunvalación de la ciudad de Córdoba subió en promedio - entre noviembre de 2007 y febrero de 2011alrededor del 50 por ciento, o sea, 10 por ciento por año. Aun así, hay zonas donde el alza fue superior al 70 por ciento $y$, en algunos casos puntuales, del ciento por ciento (Equipo de Investigación El Llano en Llamas, 2011, p. 12).

El comportamiento que describen estas variables de la situación habitacional ha sido una constante durante los últimos 20 años, dando lugar a distintas reacciones $y$ demandas por parte de los sectores populares. Sumado a la crisis económica de finales de siglo, este contexto adquirió una dimensión dramática, lo que decantó en una confluencia de demandas por trabajo, vivienda y alimentación; $y$ políticas públicas tendientes a desactivar el problema, pero con una fuerte dinámica segregacionista $y$ revalorización de tierras céntricas:

...porque hay muchas casas, de por sí, a nosotros nos hacen medio alejados porque somos ascendientes de villa (procedentes de villa), y no había espacio más cerca del centro para hacer casas. Otra, creo que el gobernador, las villas no las va a querer cerca del centro sino alejadas, porque ya saben la forma de vivir de las villas, que roban, que son mugrientos, que no todos iguales, pero por eso también estamos medios alejados. Aunque hay mucho espacio cerca del molino, pero eso es para country, trae más plata, la villa no (Asentamiento Relocalizado, Barrio Ampliación Cabildo, vecino 09, comunicación personal, Córdoba, 2008).

Sin embargo, la trayectoria de esta problemática tuvo comportamientos diferentes a lo largo del tiempo. La organización popular en torno a la vivienda tradujo las demandas y expectativas sociales de "casa propia" construyendo un horizonte de movilidad social y acceso a derechos "vulnerados". El problema de la vivienda provocó, a finales de los años 80 en Córdoba, la multiplicación de organizaciones populares que se conformaron en torno a la gestión de las necesidades básicas (alimentación, vestimenta, agua, luz, etc.). Esto implicó una creciente organización territorial para resolver, de modo comunitario, los problemas cotidianos. Al mismo tiempo, un consistente posicionamiento en el espacio público como actores con gran capacidad de movilización y control territorial.

Acá en la Villa por ejemplo 10 años atrás no teníamos agua, entonces la gente era una cosa así que peleaban todo el santo día y se organizaba alrededor del agua, llegó un momento que la villa estaba sitiada porque no había agua, entonces se cortaban las rutas por todos lados bueno, pero eran todos los vecinos no era una organización, una cosa real, una necesidad básica que no la tenían y bueno se organizaron y así lograron este tener el agua potable (Movimiento Piquetero, Unión de Organizaciones por los Derechos Humanos, Piquetero 01, comunicación personal, 2005).

En ese contexto es que cobran fuerza las demandas sociales por "acceso a la ciudad" (Ciuffolini, 2007). Un concepto que condensa el derecho a tierra, vivienda, salud, educación y servicios básicos. Simultáneamente, ante la amenaza que esta demanda representaba para la estabilidad de los gobiernos, es que comienzan a activarse diferentes dispositivos de regulación. En ese marco surge, a principio de los 
años 90 en Córdoba, lo que se denominó "Mesa de Concertación de Organizaciones de Base", un espacio institucional, con presupuesto público, que supuso la gestión colegiada de la política de vivienda e infraestructura social entre los sectores populares organizados y el gobierno (Avalle e Ibáñez, 2011).

En el apartado anterior, se menciona que dos actores protagónicos de finales de siglo fueron las asambleas barriales y los movimientos piqueteros. Los diez años que le antecedieron tuvieron como principales referentes a las organizaciones barriales y territoriales de los sectores populares cordobeses. Organizaciones que se conformaban en torno a la gestión de necesidades básicas como la alimentación, la salud, la vivienda, que fueron articulándose entre sí, logrando conformar dos frentes barriales que movilizaban a más de 100 barrios de la ciudad. Ellos son la Unión de Organizaciones de Base (UOB) y el Movimiento de Organizaciones de Base (МОВ), quienes luego integraron la mencionada "Mesa de Concertación".

...me dediqué mucho a lo que es llevar comedores $y . .$. mucho con el trabajo, eh, más que todo con la época de Angeloz, de Alfonsín (década del 80), fue la época más fuerte donde yo empecé a hacer trabajo porque yo veía muchas necesidades de la gente, $y$ me sumé, me... junté con un barrio de Saldán y fui a Cáritas a, de Saldán trabajé en Cáritas de Saldán un año. Entonces ahí formamos una interbarrial que se llamaba, una... que era un integrado de todos los barrios, donde este... traíamos las necesidades del barrio y veíamos concretamente que podíamos hacer por los barrios (...) Hacíamos actividades (...) hacíamos venta de empanadas, todas esas cosas, hasta que veíamos la posibilidad de comprar bolsas de harina, de azúcar, hacer pan, colaborar con los comedores (Organización Barrial, Movimiento de Organizaciones de Base, vecino 03, comunicación personal, Córdoba, 2005).

...desde sus comienzos del año 92, ha sido, digamos, por un lado, la unidad... $y$ por otro lado, acceso a la vivienda, acceso a la tierra y a la vivienda, digamos que esa ha sido la lucha más fuerte que tenía la Unión. Ese digamos, el fuerte que ha tenido (-) Eh, que no se ha dejado de discutir la problemática de la educación, la salud $y$ el trabajo, que en distintos eh... etapas, lo ha podido desarrollar, digamos, de alguna manera la Unión ha discutido profundamente pero no ha resuelto ese tema (Organización Barrial, Unión de Organizaciones de Base, vecino 01, comunicación personal, Córdoba, 2005).

A mediados de esa misma década, se genera un escenario fuertemente adverso para la protesta social. El Estado provincial reafirmaría su faz represiva y concentraría nuevamente el poder de decisión en política pública. En un contexto de crisis económica y fiscal significativo, con crecientes niveles de desempleo y pobreza, la gestión del conflicto abandona el lenguaje del diálogo y la "concertación". En este marco se despliegan numerosas políticas de contención que buscaría frenar la conflictividad a partir de una proliferación de recursos públicos destinados a subsidios de desempleo, planes alimentarios, pensiones, etc., junto con una permanente práctica de descalificación pública a los movilizados y el asedio a sus dirigentes con el objetivo de cooptarlos.

Si estos intentos no daban los resultados esperados, la represión directa asumía el protagonismo. El problema que se avecinaba era la confluencia de demandas y reivindicaciones sociales en los espacios públicos. Los relatos en este caso muestran esas confluencias donde organizaciones barriales, trabajadores desocupados, sindicatos, entre otros, comienzan a delinear un enemigo común.

Dos procesos que, si bien se muestran separados, encuentran un lenguaje común para construir su proyecto de futuro. Así, la demanda por trabajo $y$ por vivienda contiene un lenguaje colectivo que condensa deseos y expectativas de amplios sectores sociales que pretenden ser parte de "proyectos políticos" que los contengan. Sin embargo, la traducción de esas demandas resultó en un proceso de 
permanente fragmentación y despolitización de los actores colectivos.

Es como que en el Estado se da una estrategia integral para destruir el movimiento piquetero... (-) Sí. Algunos se han apurado, de este lado, de decir "El corte de ruta no va más". Tampoco es así, (...) en realidad el ESTADO va haciendo doctrinas de nuestras luchas, $y$ en cuestión de eso nos reprime de distintas formas, nosotros también tenemos que ir haciendo doctrinas pero... eso no significa descreer de las mejores herramientas de lucha que en los últimos años ha parido el pueblo y que no solo están tomadas por... han sido tomadas por el movimiento piquetero, sino también por los trabajadores ocupados, por los docentes, acá lo vimos en Córdoba, lleno de piquetes y cortes (Organización Piquetera, Coordinadora de Trabajadores Desocupados Aníbal Verón, Piquetero 08, comunicación personal, Córdoba, 2005).

Como consecuencia de esto, la política de impugnación transmutó en una política de gestión, con la consecuente despolitización de los espacios colectivos de base. El dispositivo de gobierno actuó, de este modo, traduciendo el reclamo popular en la gestión misma de las decisiones públicas, disminuyendo el potencial de conflicto. La administración se convirtió en una carga para los sectores organizados, restando espacio para el debate político. Desactivada la amenaza mediante la desorganización, vino un segundo proceso que consistió en la exclusión del espacio político.

...al entrar un gobierno (provincial) que fue comprando toda la dirigencia ¿sí? (...) comprando los dirigentes fuertes, los dirigentes que había... que había con fuerza de lucha, y bueno, los fue rompiendo (...) porque si vos te ponés a ver, hoy no tenemos una movilización en la calle (Organización Barrial, Movimiento de Organizaciones de Base, vecino 03, comunicación personal, 2005).
Los relatos que continúan narran el proceso de desactivación que sufrieron las organizaciones de base a finales de los 90 , bajo el mandato del gobierno peronista de De la Sota en la provincia. Estas organizaciones experimentan, en poco tiempo, la pérdida de influencia en los espacios institucionales, la pérdida de recursos a cambios de financiamiento para nuevas obras de infraestructura social que no lograrían capitalizar como propias, y el quiebre de solidares dentro de sus propias bases.

...yo tengo un problema con la cooperativa mía, nosotros tenemos un plan de vivienda $y$, después, compramos otras parcelas de tierra $y$, entramos en los nuevos planes, en los nuevos barrios, entonces el gobierno nos hizo la estructura $y$ después salió, políticamente a venderlo como que eso era los nuevos barrios que él daba, cuando la tierra es nuestra. Entonces nosotros tenemos dos cosas, la gente que vive de un nuevo plan de vivienda dicen, a mí la casa me la dio el gobierno, pero tenemos la otra parte que el gobierno no le va a escriturar, le va a escriturar la cooperativa, porque quien tiene la (...) de propiedad es la cooperativa. Entonces, hasta en eso los quebró, nos quebró como organización, porque nosotros, un montón de años de lucha, 5 años de lucha para conseguir la tierra para un nuevo plan de vivienda, cuando él entra (en 1999), se hace un acuerdo político, dentro de la cooperativa de nosotros con ellos, hace un pacto político donde le donaban cuarenta lotes a con tal de que el gobierno diera la estructura. Y los enganchó ahí, nos dio colegio, nos dio alumbrado público, nos dio, nos dio asfalto, nos dio todo, pero donde nos dejó pegados, el gobierno diciendo que era un nuevo barrio, estructura de nuevo barrio y nos enfrentábamos como que ese nuevo plan de vivienda era el nuevo de De La Sota (Organización Barrial, Movimiento de Organizaciones de Base, vecino 04 , comunicación personal, 2005). 
..lo que nosotros vemos es que de parte del estado siempre está el intento de institucionalizarnos... como por ejemplo... ellos te dan este subsidio para la copa de leche... a partir de ahora se llama Centro infantil y centro de cuidado infantil... este... y te pasan cuando ellos quieren, $y$ te dicen qué tipo de niños tenés que tener y con que (...) tenés que trabajar... sos una especie de gestor del Estado... (risas) cuando ellos no ponen el lugar, no ponen el esfuerzo, no organizan la gente... ponen la plata, que además no es la cantidad de plata que tienen que poner... pero vos trabajás de acuerdo a los criterios de ellos... tanta gente... tanto chicos acá... tanto chicos acá (Movimiento Piquetero, Movimiento Teresa Rodríguez, piquetero 01, comunicación personal, Córdoba, 2005).

Una vez desactivada la capacidad de movilización mediante la cooptación y ruptura de las organizaciones de base, la demanda colectiva de vivienda queda completamente desarticulada. La necesidad no desaparecía, pero ya no había organización ni articulación popular que la sostuviera en el espacio público. La ausencia del conflicto permitía, así, la resolución de un problema gestado directamente desde las instancias institucionales.

En este marco aparecen un conjunto de políticas cuya tendencia sería la de desactivar la demanda central: el empleo, la alimentación $y$ el techo. A nivel nacional, se implementa a mediados de 2002, el "Plan Jefas y Jefes de Hogar Desocupados" ; a nivel local, el mega-plan de viviendas "Mi casa, mi vida" financiados por el BID. El primero exigió una reincorporación del beneficiario a la disciplina laboral: prestación de servicios en dependencias

4 Programa público que supuso la transferencia de dinero hacia los beneficiarios, y como contrapartida, la retribución de horas de trabajo, controles sanitarios y educativos.

5 Programa de viviendas destinado a sectores "vulnerables" y en "riesgo ambiental" consistente en la relocalización de los asentamientos populares y el otorgamiento de una vivienda familiar. públicas, control de salud y reinserción en el sistema educativo. En definitiva, una sistemática regulación del individuo desempleado.

El segundo, el plan de viviendas, fue implementado de manera vertiginosa e inconsulta, a través de la creación de barrios populares que tenían dos características clave: situarse en las periferias de la ciudad y contar con la presencia de todas las dependencias del Estado (policía, ministerios, escuelas, comedores). Esto se tradujo en una perfecta política securitaria destinada a la regulación del espacio y el desplazamiento de la población. No obstante, ello no implicó o detuvo el creciente problema habitacional, sino todo lo contrario ${ }^{6}$.

La intensiva política de revalorización territorial promovió la expulsión de poblaciones de sus lugares de residencia sin un nuevo destino, dando lugar a la reaparición de las tomas de tierras que se habían vivido 15 años atrás. Las tomas de tierra son procesos colectivos donde un grupo de personas, generalmente sin acceso a tierra $y$ vivienda, decide asentarse en tierras desocupadas, sin dueño aparente, no delimitadas, sin obras de infraestructura, $y$ construir ahí una vivienda o lugar de cobijo.

...y es como que, viste cuándo vos decís 'dios los cría, ellos se juntan y el viento los amontona', y bueno, nos amontonó en este caso acá... y yo es cierto, yo me sentí excluida de un montón de... del sistema... nos pateaba para afuera, no entrábamos ni en la clase media, ni en la media baja, ni en ninguna clase, no existíamos y bueno (Toma de Tierra, Icho Cruz, vecino 04, comunicación personal, Córdoba, 2012).

El crecimiento de asentamientos informales en el último tiempo es significativo. En la actualidad existen en la provincia 238, registrándose entre el 2001-2010 un fuerte crecimiento poblacional (62\%) en los ya existentes, más que emergencia de nuevos asentamientos. Del total de los asentamientos, 119 se encuentran en la ciudad de Córdoba (Relevamiento de asentamientos informales de la provincia de Córdoba, Un Techo para mí País- Argentina, septiembre de 2011). 
Y siempre le hablo a mi hijo: 'Mirá tenemos la casa porque se ganó así con el sacrificio de nosotros, papá, mamá, luchó, vos también luchaste'. Resistí, todos los días. Y cuando vienen familias le digo 'esta es mi casa, tengo tanto luchar, tanto venir acá'. Y es así. Y uno tiene su casa, tiene el orgullo de decir vivo allá (Toma de Tierra, Barrio Ampliación Cabildo, vecino 08, comunicación personal, Córdoba, 2012).

...el tema de la vivienda siempre para nosotros representaba un problema porque no podíamos... muchas veces, por ejemplo, el último año, que estuvimos alquilando, que fue al anteaño pasado, llegó un momento que hubo meses en los que teníamos que decidir entre comprarle un par de zapatillas a Brisa y pagar el alquiler completo (Toma de Tierra, Icho Cruz, vecino 06, comunicación personal, Córdoba, 2012).

\section{CONCLUSIONES}

Con frecuencia las situaciones de desigualdad y exclusión en las sociedades contemporáneas son abordadas bajo una dinámica que focaliza de modo permanente al individuo "vulnerable" o "pobre" (Bravo, 2001; Indec, 2000; Macadar y Mendive, 1997). Hablar de pobreza resulta, incluso, reiterativo, dada la numerosa producción bibliográfica sobre el tema. Sin embargo, desde esta perspectiva, se considera al menos necesario diferenciarnse de estos conceptos.

Pobreza habitualmente es un término que agrupa un conjunto de estrategias de medición y agregación de categorías que hacen foco en la "carencia" del individuo; efectúa una lectura estática de las condiciones de vida de la población; construye al pobre como un conjunto homogéneo de población marginada o excluida de la sociedad. Sin embargo, las voces de esos pobres dan cuenta de una dinámica diferente: en primer lugar, exigen que se hable, en todo caso, de pobrezas - en plural-, en tanto estas se encuentran ancladas a múltiples y diversas experiencias cotidianas; $y$ por otro lado, entenderlas como posiciones determinadas por la posesión de capitales dentro de una estructura específica de relaciones, es decir, dentro de la sociedad $y$ no excluidos de esta.

Por su parte, el concepto de "vulnerabilidad" en políticas sociales es problemático en tanto habilita dinámicas individualizantes, a la vez que totalizantes, de los sujetos beneficiarios/destinatarios. Por un lado, el "beneficiario" es objeto de un tratamiento diferencial al del resto de la población, dado que su principal atributo es la carencia de todo tipo de recurso o capital. De este modo, el acceso a la cobertura de la política pública no aparece como un derecho, sino como una compensación de daños (sociales), una condición precaria del ciudadano neoliberal.

Simultáneamente, cada situación de vulnerabilidad individual es inscripta en una lógica más global de tratamiento, que persigue la permanente normalización de la desigualdad social que la provocó. Así, configuraciones del espacio social que asumen un carácter dominante son permanentemente legitimadas por un discurso compensatorio proveniente de la estatalidad, $y$ en este sentido, es posible pensar el carácter (des)igualatorio que asume la política pública frente a las tensiones del presente.

No obstante, la presencia del concepto de "vulnerabilidad" en los discursos públicos fue un punto para problematizar esta indagación. Los riesgos que supone esta perspectiva están en su misma definición. Asume al vulnerable como aquel individuo potencialmente en riesgo de algo que constituye una amenaza para sí, un estado de "incertidumbre, indefensión e inseguridad" (Brusso, 2001, p. 3). Bajo ese supuesto desaparece la construcción del beneficiario como ciudadano portador de derechos, como el de la salud, la educación, etc., y por tanto, una categoría de carácter universal, para pasar a ser un sujeto en potencial amenaza de exclusión de "asistencia" educativa, de salud, etc., y por tanto, un individuo en riesgo, un individuo vulnerable.

Desde esa perspectiva, todos se ven expuestos a riesgos (Beck, 1998) de modo que 
solo es necesario ir identificando los mecanismos (parches) para atender cada problemática y situación. En este marco, "vulnerable" fue un concepto que penetró tanto en las oficinas en Washington y Nueva York de los organismos internacionales, como en las barricadas y asentamientos protagonizados por los sectores populares. Sin embargo, como era de esperar, la mirada estuvo puesta en ejes diferentes.

Espacios como el G7 y en menor medida el G20 vienen a reemplazar los mandamientos del Consenso de Washington. El foro de los 20 países se convirtió en el escenario de reclamos de los países menos desarrollados, $y$ en la reafirmación de medidas financieras para sostener modelos que de modo permanente están mostrando la inviabilidad de, parafraseando a Touraine (1998), una "vida juntos".

Por el otro lado, desde el llano, los sectores populares organizados han posicionado nuevamente las demandas de inclusión en el debate y radicalizado las prácticas de impugnación social. Ambos conceptos se encuentran en constante disputa, constituyen un modo de (no) nombrar los conflictos sociales y de in/excluirlos. Aparece de esta manera una tensión clave, permanentemente irresuelta, de la conformación de los espacios públicos y la definición del sentido de la política, o su capacidad de definir los rumbos de una sociedad.

En el breve recorrido que se intentó hacer sobre la situación del caso argentino, $y$ la provincia de Córdoba en particular, vista esta desde la perspectiva de los sectores populares, se aporta una serie de elementos para pensar y problematizar las consecuencias que provocan las políticas públicas, independientemente del objetivo que persigan.

Los relatos de los entrevistados, que recuperan más de 20 años de experiencias del campo popular, advierten sobre la tensión que permanentemente se presenta cuando los espacios de decisión y acción pública se ven cuestionados desde la propia base social. Sin duda, los recursos que los sectores populares organizados logran obtener de la estatalidad constituyen uno de los pilares para fortalecer su estructura interna, su capacidad de movilización y de negociación ante los funcionarios públicos. Sin embargo, esta forma alternativa de la gestión de los problemas, que implica la intermediación entre individuos $y$ estados a partir de organización de los sectores afectados, representa para la estatalidad un riesgo, una amenaza al control que busca fijar sobre estas poblaciones.

Se percibe en los textos de las políticas estatales, aun $y$ especialmente en las provinciales, que las personas en cuestión no carecen de Estado, sino todo lo contrario, tienen Estado de sobra, puesto que se encuentran inscriptos en una nueva técnica gerencial, o gerenciados por una nueva tecnología de control y/o represión social. La presencia estatal, mientras tanto, no garantiza precisamente derechos: en todos los documentos oficiales y publicaciones de organismos internacionales, al mismo tiempo que se ofrecen oportunidades, se producen historias de vida típicas de todo lo que falta para que un sujeto este en condiciones de disfrutar de su condición de ciudadano.

Cuando la organización popular constituye una clara amenaza a la legitimidad de los proyectos políticos dominantes, los mecanismos estatales se concentran en provocar la fractura, ruptura y desmovilización de estas experiencias colectivas. Esto lo hacen a partir de múltiples tácticas en el escenario público, ya sea a partir de la cooptación de sus dirigentes, el involucramiento de esas organizaciones en prácticas cada vez más burocratizadas, o la intervención directa en el territorio persiguiendo la fractura de la base de apoyo. Pero cuando estos mecanismos no son suficientes, el espacio público se convierte en un campo de batalla, donde la represión opera como la única respuesta del Estado a las demandas sociales.

El escenario que se presenta es el de un doble aprendizaje, donde el Estado hace doctrina de las luchas y la organización popular, y estas hacen de su práctica y de la relación con el Estado una caja de herramientas y un estado de situación que fija permanentemente nuevos puntos de partida e instancias de demandas sostenidas con estrategias más radicales, más móviles, y formas organizativas más flexibles. Esto les permite con relativo éxito, escapar a la desactivación, creando un escenario más 
participativo, más politizado y con actores fuertemente empoderados.

De ahí que se sostenga que "cuando pensamos en una democracia sólida, $y$ reclamamos por instituciones que sean capaces de organizarla, debemos garantizar los espacios de libertad para aquellas personas que están luchando por una sociedad más justa" (Equipo de Investigación El Llano en Llamas, 2011, p. 22).

\section{REFERENCIAS}

Aspiazu, D. y Basualdo, E. (2012). Transformaciones estructurales de la economía argentina. Una aproximación a partir del panel de grandes empresas 1991-2005. Buenos Aires: Programa Naciones Unidas para el Desarrollo (PNUD). Recuperado de http://www.undp.Org.Ar/docs/libros_y_ publicaciones/flacso.pdf

Avalle, G. (2010). Las luchas del trabajo: sentidos y acciones de docentes, meretrices y piqueteros en Córdoba. (Tesis de Maestría en Sociología). Serie Thesys. EDUCC: Córdoba.

Avalle, G. y Brandán Zehnder, M.G. (2010). Entre la asistencia, la promoción y la inclusión. Dilemas de las políticas de empleo post-convertibilidad en Argentina. En III Jornadas de Estudios Políticos. 17 al 19 de noviembre. Universidad Nacional General Sarmiento. Los Polvorines. ISBN 978-987-26398-0-8.

Avalle, G., De la Vega, C. y Ferrero, M.M. (2009). Ciudadanía, técnicas de gubernamentalidad y degradación de derechos: lo planes laborales pos 2001 en Argentina. Foro Internacional "Territorialidades Locales-Regionales y Métodos Posibles de Resolución de Conflictos". 29 al 31 de octubre. Córdoba, Argentina.

Avalle, G., y Ibañez Mestres, G. (2011). Gestionar, concertar o decretar la provisión de viviendas en Córdoba. Análisis de los actores en el gobierno de lo habitacional. En Núñez, A. y Ciuffolini, M.A. Política y territorialidad en tres ciudades argentina [pp. 61-84]. Buenos Aires: Ediciones El Colectivo.

Beck, U. (1998). Sociedad De Riesgo. Barcelona: Paidós Básica.
Busso, G. (2001). Vulnerabilidad social: nociones e implicancias de politicas para Latinoamérica a inicios del siglo $X X I$. ONU-CEPAL. Santiago de Chile. Recuperado de http://www.redadultosmayores.com.ar/buscador/files/ ORGIN011.pdf

Bravo, J. (2001). Estimaciones de Ingreso y Pobreza para áreas geográficas menores: Avances recientes en América Latina y el Caribe. Notas de Población, año 71, nro. 71. Santiago de Chile: CEPAL. Pp. 139-148.

CEPAL. (2009). Panorama social de América Latina 2009. Santiago: CEPAL.

Ciuffolini, M.A. (2007). Luchas urbanas por la tierra. Anuario IX del Centro de Investigaciones Jurídicas y Sociales, pp. 443-459. Facultad de Derecho y Ciencias Sociales. Universidad Nacional de Córdoba.

Comisión Económica Para América Latina y el Caribe (CEPAL). (2011). La inversión extranjera directa en América Latina y el Caribe 2010. Santiago de Chile: CEPAL. Recuperado de http://www.eclac.cl/publicaciones/xml/9/43289/2011-322-LIE2010-WEB_ULTIMO.pdf

Dagnino, E. (2006). Sociedad civil, participación y ciudadanía en Brasil. Seminario de Gestión de procesos culturales y construcción de lo público. Universidad Nacional de Colombia, Universidad Externado de Colombia, Pontificia Universidad Javeriana y Universidad del Rosario. Colombia. Recuperado de http://www.culturarecreacionydeporte. gov.co/cultura_recreacion_y_deporte/sistema_distrital_de_cultura/diplomado/ Ponencia\%20Evelina\%20Dagnino.pdf

Equipo de Investigación El Llano en Llamas. (2011). Informe Preliminar. Tomas de tierras en la provincia de Córdoba. Argentina. Recuperado de https:// es.scribd.com/doc/143931607//TOMASDE-TIERRAS -EN-LA-PROVINCIADECORDOBA

Foucault, M. (2006). Seguridad, territorio, población. Buenos Aires: Fondo de la Cultura Económica. 
Gudynas, E. (2009). Diez tesis urgentes sobre el nuevo extractivismo. Contextos y demandas bajo el progresismo sudamericano actual. En AA.vv., Extractivismo, política y sociedad, pp. 187-225. Quito: Centro Andino de Acción Popular. Recuperado de http://www.ambiental.net/publicaciones/ GudynasNuevoExtractivismo10Tesis09 x2.pdf

INDEC. (2000). El estudio de la pobreza con datos censales. Nuevas perspectivas metodológicas. Trabajo presentado en el $5^{\text {to }}$ Taller Regional del Mecovi. México, 6-8 de junio.

Katz, C. (2010). Variedad de políticas económicas. Elementos para una lectura crítica de América Latina, pp. 23-37. Espacio Crítico Centro de Estudios. Recuperado de http://es.scribd.com/doc/39354682/ Katz-Claudio-Elementos-para-unalectura-Critica-de-America-Latina

Macadar, D. y Mendive, C. (1997). Estimación indirecta de ingresos y proporción de hogares pobres: una metodología para jerarquizar áreas menores. Notas de población, 25(66), 111-155. Santiago de Chile: CEPAL.

Mecle, E. (2010). Politicas públicas y razón populista. El modelo progresista de Kirchner: 2003-2007. Buenos Aires: Proyecto Editorial.

Ministerio de Desarrollo Social. (2007). La Bisagra. Politicas Sociales en acción.
Buenos Aires: Ministerio de Desarrollo Social.

Poulantzas, N. (2001). Poder político y clases sociales en el Estado capitalista. México: Siglo XxI.

Rodriguez, M. y Taborda, A. (2009). Análisis de Politicas públicas. Formación, estilos de gestión y desempeño: Políticas de Vivienda. Córdoba 1991-2007. Córdoba: Brujas.

Seoane, J. (2012). El retorno de la crisis y la ofensiva extractivista en América Latina [CLASE]. Curso virtual "Extractivismo y resistencias sociales en Nuestra América: conflictos en torno a los bienes comunes y horizontes emancipatorios" (Programa Latinoamericano de Educación a Distancia). Buenos Aires: Centro Cultural de la Cooperación.

Sidicaro, R. (2006). La crisis del Estado y los actores políticos y socioeconómicos en la Argentina (1989-2001). Buenos Aires: Eudeba.

Svampa, M. (2005). La sociedad excluyente. La Argentina bajo el singo del neoliberalismo. Buenos Aires: Taurus.

Touraine, A. (1998) ¿Podremos vivir juntos? Buenos Aires: FCE.

Fecha de ingreso: 17/10/2018 Fecha de aprobación: 21/05/2019 